\title{
Hipokalemik periyodik paralizi ile başlangıç gösteren primer Sjögren sendromu
}

\author{
Primary Sjögren's syndrome presenting with hypokalemic periodic paralysis

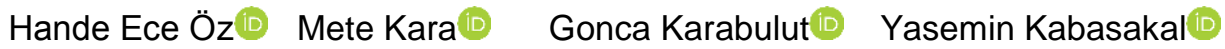 \\ Ege Üniversitesi Tıp Fakültesi, İç Hastalıkları Anabilim Dalı, Romatoloji Bilim Dalı
}

\section{Öz}

Primer Sjögren sendromu (PSjS) heterojen klinik bulgularla seyreden kronik sistemik otoimmün bir hastalıktır. PSjS'de renal tutulum sıklığı \%4.9 ve renal tutulum öncesi ortalama hastalık süresi iki yıl olarak bildirilmiştir. En sık renal tutulum tübülointerstisyel nefrit (TIN) olup daha az sıklıkla glomerülonefrit de görülebilmektedir. TIN bazı hastalarda izole elektrolit bozukluğu, distal renal tübüler asidoz (dRTA) yaparken bazı hastalarda ise son dönem böbrek yetmezliğine yol açabilmektedir (6). dRTA'un ise en sık klinik bulgusu hipokalemik paralizidir, bunun yanında nefrokalsinozis ve metabolik kemik hastalığına da yol açabilir. Bu yazıda PSjS'nin nadir bir başlangıç şekli olan renal tübüler asidoz ve hipokalemik periyodik paralizi olgusunu sunmaktayız.

Anahtar Sözcükler: Primer Sjögren sendromu, hipokalemik periodik paralizi.

\begin{abstract}
Primary Sjögren's syndrome (PSjS) is a chronic systemic autoimmune disease with heterogeneous clinical findings. The incidence of renal involvement in PSjS was reported as $4.9 \%$ and the mean duration of disease before renal involvement was two years. The most common renal involvement is tubulointerstitial nephritis (TIN) and less frequent glomerulonephritis. TIN may lead to isolated electrolyte disorder and distal renal tubular acidosis (dRTA), while in some patients it may lead to end-stage renal failure (6). The most common clinical manifestation of DRTA is hypokalemic paralysis, which may lead to nephrocalcinosis and metabolic bone disease. We report a rare initial form of PSjS presenting with renal tubular acidosis and hypokalemic periodic paralysis.
\end{abstract}

Keywords: Primary Sjögren's syndrome, hypokalemic periodic paralysis.

\section{Giriş}

Primer Sjögren sendromu (PSjS), heterojen bulgularla seyreden kronik sistemik otoimmün bir hastalıktır. Prevelansı \%0.01 - \%0.09 ve insidansı 100 binde 3.111.8 'dir (1). Hastaların \%95'i sikka semptomları ile başlangıç gösterse de ekstraglandüler bulgular ile başlangıç da görülebilmektedir (2). Renal tutulum sıklığı \%4.9 olarak bildirilmiştir (2). En sık renal tutulum tübülointerstisyel nefrit olup daha az oranda glomerülonefrit görülebilmektedir (3).

\section{Olgu}

51 yaşında kadın hasta, 30 yıl önce polidipsi, poliüri, kas güçsüzlüğü ve dispneyle acil servise başvurmuş. Dört ekstremitede flask paralizi saptanan hastanın laboratuvar sonuçlarında normal anyon gap'li metabolik asidoz $(\mathrm{pH}: 7,29$ HCO3: 14meq/l, pCO2:28mmHg, pO2:100 $\mathrm{mmHg}$ ), hipokalemi (K: 1,9 mEq/L), alkali idrar ve idrar anyon gapte artış (pH: 7 ve idrar anyon gap:17) tespit edilmiş.

\footnotetext{
Yazışma Adresi: Hande Ece Öz

Ege Üniversitesi Tıp Fakültesi İç Hastalıkları Anabilim Dalı, Romatoloji Bilim Dalı

E-mail: handeceoz@hotmail.com
}

Amonyum klorid yükleme testi pozitif olarak saptanan hastaya distal renal tübüler asidoz (dRTA) tanısı konulmuş. Hastanın paralizi tablosu, potasyum ve sodyum bikarbonat replasmanı sonrası 48 saat içinde dramatik olarak düzelmiş. İki yıldır tekrarlayan paralizi atakları, ağız kuruluğu, göz kuruluğu, fotosensitivite ve Raynaud fenomeni tanımlayan hastanın, ANA 1/640 granüler, anti-ro: $29 \mathrm{RU} / \mathrm{mL}$ ve anti-la: 4,8 RU/mL, RF: $102 \mathrm{IU} / \mathrm{mL}$ olarak saptanmış. Schirmer testi $2 \mathrm{~mm} / 5 \mathrm{dk}$ ve tükürük bezi biyopsisi Chisholm evre 4 ve renal biyopsi tübülointerstisyel nefrit (TIN) olarak sonuçlanmış. PSjS'na bağlı TIN saptanan hastaya oral siklofosfamid, $250 \mathrm{mg}$ klorokin fosfat, yüksek doz metilprednizolon ve $\mathrm{NaHCO} 3, \mathrm{KCL}, \mathrm{CaCO} 3$ başlanmış. Özgeçmişinde sigara, alkol kullanımı yok, bir canlı doğum mevcut. Soy geçmişte annesinde diabetes mellitus dışında özellik yok. Takiplerine düzenli gelmeyen hasta 2002 yılında yaygın ağrı, proksimal kaslarda güçsüzlük şikâyetiyle başvurdu. Trendelenburg yürüyüşü, ekstremitelerde hiperaljezi, proksimal kaslarda güçsüzlük saptanan hastanın laboratuvar sonuçlarında BUN $200 \mathrm{mg} / \mathrm{dl}$, kreatinin $4,35 \mathrm{mg} / \mathrm{dL}, \mathrm{K}: 2,1 \mathrm{mEq} / \mathrm{L}$, kalsiyum: $6,5 \mathrm{mg} / \mathrm{dL}$, fosfor: $3,3 \mathrm{mg} / \mathrm{dL}$, albümin: $2,6 \mathrm{~g} / \mathrm{dL}$, bikarbonat: 16,2 $\mathrm{mEq} / \mathrm{L}$, alkalen fosfataz: $672 \mathrm{u} / \mathrm{l}$ olarak saptand. Idrar testinde ph:7 ve mikroskobisinde silendir olmaksızın bol eritrosit ve silme lökosit saptandı. Pelvis grafisinde sağ femurda Milkman fraktürü görüldü. Kemik biyopsisi osteomalazi ile uyumlu saptandı. TIN bulguları devam ettiğinden $100 \mathrm{mg} / \mathrm{gün}$ azatioprin ve kalsitriol başlandı. 2009 yılında hastaya renalreplasman tedavisi başlandı. 
TIN'e bağlı son dönem böbrek yetmezliği gelişen hastaya renal transplantasyon planlanmaktadır. Hastadan tıbbi verilerinin yayınlanabileceğine ilişkin yazılı onam belgesi alındı.

\section{Tartışma}

PSjS'nda renal tutulum sıklığı \%4.9 olup renal tutulum öncesi ortalama hastalık süresi iki yıl olarak bildirilmiştir (2). Renal tutulum olan hastaların \%40'ında başlangıçta elektrolit bozukluğu, dRTA, Fanconi sendromu, nefrolitiyazis, poliüri, proteinüri, hematüri, renal fonksiyon defekti, aktif idrar sedimenti mevcut olup, \%60'ında renal bulgular öncesi sikka semptomları bulunmaktadır $(2,3)$. PSjS'nin neden olduğu TIN bazı hastalarda izole elektrolit bozukluğu, dRTA yaparken bazı hastalarda ise son dönem böbrek yetmezliğine yol açabilmektedir (6). DRTA'nın ise en sık klinik bulgusu hipokalemik paralizidir, bunun yanında nefrokalsinozis ve metabolik kemik hastalığı da gelişebilir (5). Ayrıca PSjS hastalarının üçte birinde belirgin metabolik asidoza yol açmaksızın izole idrar asidifikasyon bozukluğu ile seyreden inkomplet RTA olduğu saptanmıştır (4). Bizim hastamız da periyodik paralizi tablosu ile hastaneye başvurmuş olmakla birlikte öncesinde sikka semptomları, fotosensitivite, Raynaud fenomeni gibi semptomlar mevcuttur. Histopatolojik olarak TIN renal interstisyumu ve renal tübülleri saran CD4+ lenfosittik infiltrasyonla karakterizedir (5). dRTA hastalarının bazılarında biyopsi bulgularının normal olması patogenezde karbonik anhidraz, HATPaz, $\mathrm{NaCl}$ kotransportera karşı antikorların olabileceğini düşündürmektedir (5). Anti-ro ve anti-la antikorlarının ekstraglandüler tutulum sıklığını arttırdığı bilinmekle birlikte renal tutulum ile ilişkisi net değildir. Yeterli çalışma olmadığından PSjS'de görülen TIN tedavisinde yaygın olarak kabul edilen bir yaklaşım bulunmamaktadır. Steroid tedavisinin etkin olduğu gösterilmiş olmakla birlikte immünsupresiflerin etkinliği konusunda çelişkiler mevcuttur. Steroid monoterapisine dirençli, başlangıçta renal fonksiyonlarında bozukluk ve yüksek IgG aktivitesine sahip hastaların siklofosfamid ve sistemik steroid kombinasyonundan tek başına steroid tedavisine göre daha çok faydalandığı gösterilmiştir (6). Başka bir çalışmada da mikofenolat mofetil ve sistemik steroid kombinasyon tedavisinin renal fonksiyonlarda düzelme sağladığı saptanmıştır (4). Azatioprinin de renal fonksiyonlarda düzelme sağladığı olgu sunumları şeklinde bildirilmiştir (4). Sonuç olarak PSjS ekstraglandüler semptomlarla başlangıç gösterebilir, bunların farkında olmak erken tanıya olanak sağlar.

\section{Kaynaklar}

1. Qin B, Wang J, Yang Z, et al. Epidemiology of primary Sjögren's syndrome: a systematic review and meta-analysis. Ann Rheum Dis 2015;74:1983-9.

2. Yang HX, Wang J, Wen YB, et al. Renal involvement in primary Sjögren's syndrome: A retrospective study of 103 biopsy-proven cases from a single center in China. Int $J$ Rheum Dis 2018(1):223-9.

3. Jain A, Srinivas BH, Emmanuel D, Jain VK, Parameshwaran S, Negi VS. Renal involvement in primary Sjogren's syndrome: a prospective cohort study. Rheumatol Int 2018;38(12):2251-62.

4. Evans RD, Laing CM, Ciurtin C, Walsh SB. Tubulointerstitial nephritis in primary Sjögren syndrome: clinical manifestations and response to treatment. BMC Musculoskeletal Disorders 2016 17:2. doi: 10.1186/s12891-015-0858-x.

5. Nocturne G, Mariette X. Advances in understanding the pathogenesis of primary Sjögren's syndrome. Nat Rev Rheumatol 2013;9(9):544-56.

6. Shen Y, Xie J, Lin L, Li X, et al. Combination cyclophosphamide/glucocorticoids provide better tolerability and outcomes versus glucocorticoids alone in patients with Sjogren's associated chronic Interstitial nephritis. Am J Nephrol 2017;46(6):473-80. 